\title{
EXTRACTIVE METHOD OPTIMIZATION FOR Ligustrum lucidum THAT LEADS TO A BETTER FREE RADICAL SCAVENGING ACTIVITY
}

\author{
Teresa Delgado ${ }^{1}$, Maria Graça Campos ${ }^{2,3}$, Nelson Farinha ${ }^{1}$, Letícia M. Estevinho ${ }^{4,5}$ and \\ Ofélia Anjos ${ }^{1,6}$
}

\author{
${ }^{1}$ Centro de Biotecnologia de Plantas da Beira Interior, 6001-909 Castelo Branco, Portugal; \\ ${ }^{2}$ Observatory of Herb-Drug Interactions/ Faculty of Pharmacy, University of Coimbra, Heath \\ Sciences Campus, Azinhaga de Santa Comba, Coimbra Portugal. \\ ${ }^{3}$ Coimbra Chemistry Center (CQC, FCT Unit 313) (FCTUC) University of Coimbra, Rua Larga, \\ Coimbra, Portugal. \\ ${ }^{4}$ Portugal Center of Molecular and Environmental Biology, University of Minho, Campus de \\ Gualtar, 4710-057 Braga, Portugal \\ ${ }^{5}$ Agricultural College of Bragança Polytechnic Institut of Bragança Campus Santa Apolónia E \\ 5301-855 Bragança, Portugal. \\ ${ }^{6}$ Instituto Politécnico de Castelo Branco, 6000-084, Castelo Branco, Portugal; ofelia@ipcb.pt
}

Ligustrum lucidum Aiton is a plant with important biological properties and its berries are used in Chinese medicine with tonic effects, used as a protection against some diseases due to the presence of antioxidants [1]. No research has been done in Portuguese samples and the aim of this work was to optimize the extraction process that gives the best antioxidant activity for $L$. lucidum berries from two different regions in Portugal (Region 1: Lisbon and Region 2: Castelo Branco).

Over the years several extraction methods have been developed in order to obtain the best antioxidant extract and their choice depends on the chemical structure of the active components. For this propose three different solvents were tested: boiling water (45 min); $100 \%$ ethanol (shacked 6, 12 and 24 hours) and 50\% ethanol-water (v/v) (shacked 6, 12 and 24 hours). All experiments were performed in duplicate, at room temperature in the dark.

For berries growing in region 2 the higher extraction yields were obtained with $100 \%$ ethanol and $50 \%$ ethanol-water. No significant differences were observed between different extraction solvents or between extraction times for region 1 .

In terms of antioxidant activity, the screening method chosen was 2,2-diphenyl-1-picrylhydrazyl UV quantification at $517 \mathrm{~nm}$. The extracts with higher antioxidant activity, measured as $\mathrm{EC}_{50}$ $(\mathrm{mg} / \mathrm{ml})$, were performed with water and $50 \%$ ethanol-water. Nevertheless, with no significant differences on average, the antioxidant activity increased a little with the increase of the extraction time and the variability decrease. Given this results we propose 15 hours of extraction for all extracts performed with water and $50 \%$ ethanol-water. These results showed also that $L$. lucidum berries growing in Portugal have antioxidant potential. However, their activity varies among these two regions.

[1] Li ML, Lui ML, Feng WH. Advances in the research on the fruits of Ligustrum lucidum. Zhongguo Zhongyao Zhazhi 1994, 19 (8): 504. 

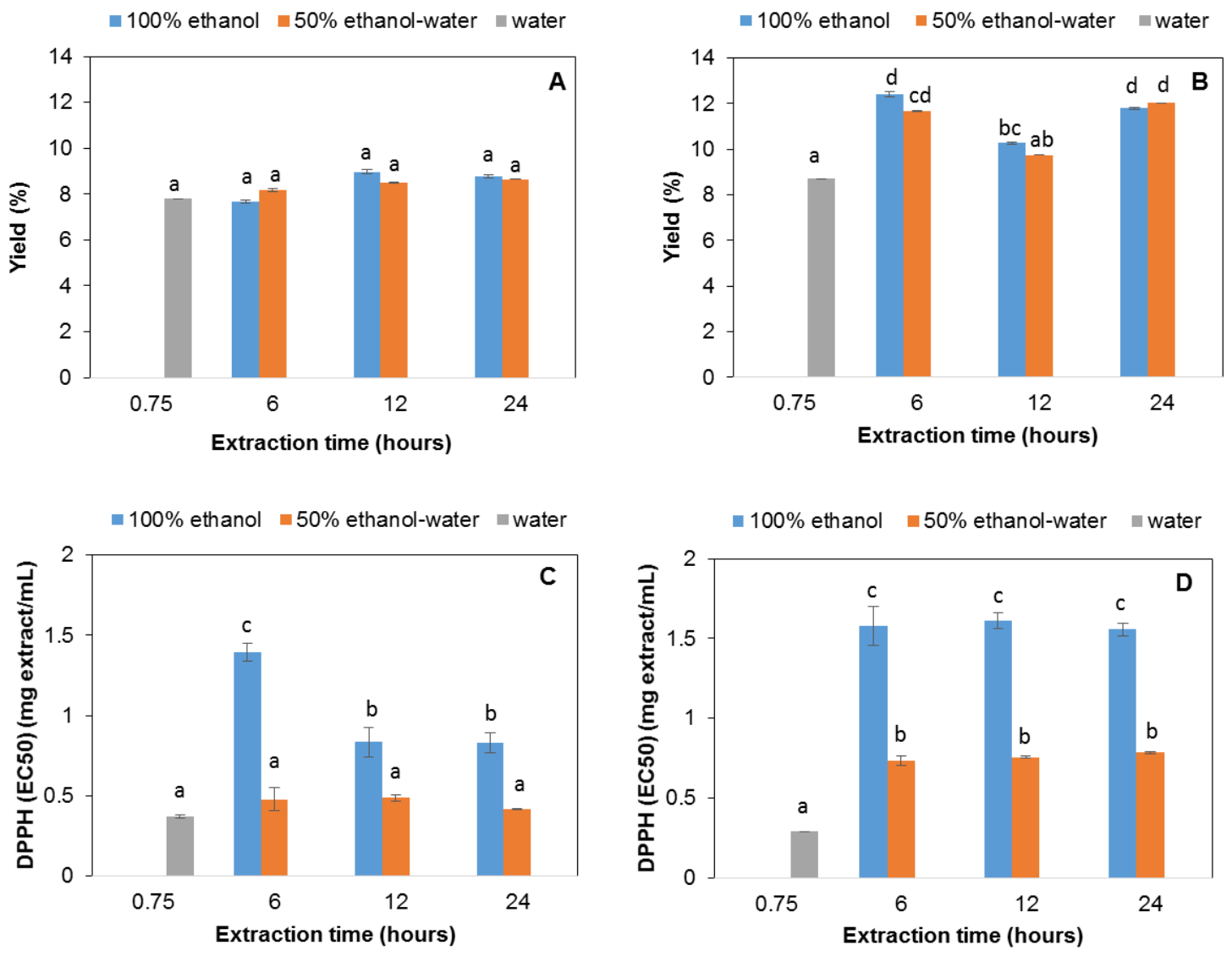

Figure 1 - Extraction yields (\%) of Ligustrum berries subjected to different extraction conditions from two different Portuguese regions: A) Lisbon and B) Castelo Branco; Radical scavenging ability (DPPH assay) of Ligustrum berries extracts, expressed as EC50 values ( $\mathrm{mg} / \mathrm{mL}$ ), obtained with different extraction conditions from two different Portuguese regions: C) Lisbon and D) Castelo Branco. 